\section{Factorial analysis of variance with unequal observations: A BASIC program for microcomputers}

\author{
JOHN P. GALLA \\ Widener University, Chester, Pennsylvania 19013
}

Factorial designs allow an experimenter to assess the combined effects of two or more independent variables simultaneously. Moreover, since these designs allow the assessment of interaction effects, a factorial experiment is more efficient and complete than a series of singlefactor studies (Winer, 1962).

Practically speaking, the one major disadvantage to the factorial design is that readily available computational methods require equal observations in all treatment combinations. Although the prudent experimenter will make every effort to ensure equal observations, situations arise in which equal observations are not possible.

For those situations in which equal observations do not obtain, methods and procedures of analysis are available (Edwards, 1972; Lindman, 1974; Winer, 1962). However, the computational difficulty involved in carrying out these procedures is considerable, and the degree of computational difficulty increases with the number and levels of factors. ${ }^{1}$

One purpose of the present program is to provide the user a procedure whereby data from a factorial experiment with unequal observations can be easily and accurately analyzed. Moreover, since variations of such programs already exist as part of sophisticated statistical packages, such as SPSS (Nie, Hull, Jenkins, Steinbrenner, \& Bent, 1975), available on large main frames, a second purpose is to make this procedure available to the large number of experimenters whose only means of computer analysis is with a microcomputer.

The present program does not require equal observations. It computes a factorial analysis of variance for a three-factor experiment with up to five levels per factor and provides the user a complete summary ANOVA table. The program is based on a procedure by Edwards (1972) in which scores in a given cell are averaged and the mean of the cell is treated as a single observation. This procedure provides accurate approximations of the tests of significance for all main and interaction treatment effects.

Input. Any factor may be labeled A, B, or C regardless of the number of levels in that factor. The only requirement is that $A$ change least rapidly with the data and $C$ change most rapidly. This determines the order in which the cells are entered (i.e., A1-B1-C1, A1-B1-C2, A1-B2-C1, etc.).

The program requires the following information to
Table 1

Sample Output

\begin{tabular}{lcrcc}
\hline \multicolumn{1}{c}{ Source } & SS & df & MS & F \\
\hline Factor A & 817.891 & 1 & 817.891 & 79.3354 \\
Factor B & 273.734 & 1 & 273.734 & 26.5522 \\
Factor C & 689.141 & 1 & 689.141 & 66.8466 \\
A by B & 3.42578 & 1 & 3.42578 & .332301 \\
A by C & 118.322 & 1 & 118.322 & 11.4773 \\
B by C & 32.6465 & 1 & 32.6465 & 3.16671 \\
A by B by C & 12.332 & 1 & 12.332 & 1.19621 \\
Error & & 60 & 10.3093 & \\
Total & & 67 & & \\
\hline
\end{tabular}

Note-Sample data are from Edwards $(1972, p .228)$.

be placed in DATA statements: (1) the number of levels of Factors A, B, and C (in that order), (2) the total number of observations, (3) the number of cells (treatment combinations), and (4) starting with Cell A1-B1$\mathrm{C} 1$, the number of observations in a given cell, followed by the scores in that cell.

The program asks the user if instructions are required. If the answer is "yes," instructions on how to place the data in DATA statements are given. If the answer is "no," the program assumes data have been entered and computes the analysis. If no new data have been entered, analysis of the sample data is performed.

Output. Sample output is presented in Table 1. A complete summary ANOVA table is provided.

Program Language and Requirements. The program is written in Radio Shack Level II BASIC. It consists of 120 lines, including REMark and DATA statements, and requires a system with $16 \mathrm{~K}$ bytes of RAM. Individuals with a good knowledge of BASIC can reduce the core requirements of the program by removing the REM statements and incorporating short single lines into multiple-statement lines.

The program is intended for use with simple cassettebased systems. Therefore, data are read from statements embedded within the program. For individuals with disk-based systems, or for those with access to larger systems, the program can be easily modified to read data from files.

Availability. A program listing and sample run can be obtained by writing to the author at the following address: Social Science Group, Widener University, Chester, Pennsylvania 19013.

\section{REFERENCES}

EDWARDs, A. L. Experimental design in psychological research (4th ed.). New York: Holt, Rinehart \& Winston, 1972.

Lindman, H. R. Analysis of variance in complex experimental designs. San Francisco: Freeman, 1974.

LyCzAK, R. A. Elementary programming for statistics. North Scituate, Mass: Duxbury Press, 1980.

Nie, N. H., Hull, C. H., Jenkins, J. G., Steinbrenner, K., 
\& Bent, D. H. Statistical package for the social sciences (SPSS) (2nd ed.). New York: McGraw-Hill, 1975.

WINER, B. J. Statistical principles in experimental design. New York: McGraw-Hill, 1962.

\section{NOTES}

1. If observations are vastly different, it is difficult to justify doing the analysis since "independence of the treatment sums of squares depends partly on the relative numbers of observations in the cells" (Lindman, 1974, p. 101).

2. Edwards uses a two-factor experiment as an example. A three-factor program was written to provide a second example of Edward's procedure, as well as an example of the programming procedures that can be applied to any factorial experiment with any number of factors.

3. This program may be used to analyze data from a factorial experiment with equal observations. In that case, all $F$ ratios will be exactly the same as when computed using a formula that requires equal observations. A more straightforward program for factorial experiments with equal observations may be found in Lyczak (1980, p. 151).

(Accepted for publication October 6, 1981.) 